\title{
Investigation of Annealing and Blend Concentration Effects of Organic Solar Cells Composed of Small Organic Dye and Fullerene Derivative
}

\author{
Yasser A. M. Ismail, ${ }^{1}$ Tetsuo Soga, ${ }^{1}$ and Takashi Jimbo ${ }^{2}$ \\ ${ }^{1}$ Department of Frontier Materials, Nagoya Institute of Technology, Gokiso-cho, Showa-ku, Nagoya 466-8555, Japan \\ ${ }^{2}$ Research Center for Nano-Device and System, Nagoya Institute of Technology, Gokiso-cho, Showa-ku, Nagoya 466-8555, Japan
}

Correspondence should be addressed to Yasser A. M. Ismail, yasser_ami@yahoo.com

Received 17 March 2011; Accepted 7 May 2011

Academic Editor: Surya Prakash Singh

Copyright ( 2011 Yasser A. M. Ismail et al. This is an open access article distributed under the Creative Commons Attribution License, which permits unrestricted use, distribution, and reproduction in any medium, provided the original work is properly cited.

\begin{abstract}
We have fabricated bulk heterojunction organic solar cells using coumarin 6 (C6) as a small organic dye, for light harvesting and electron donation, with fullerene derivative [6,6]-phenyl- $\mathrm{C}_{61}$ butyric acid methyl ester (PCBM), acting as an electron acceptor, by spin-coating technique. We have investigated thermal annealing and blend concentration effects on light harvesting, photocurrent, and performance parameters of the solar cells. In this work, we introduced an experimental method by which someone can easily detect the variation in the contact between active layer and cathode due to thermal annealing after cathode deposition. We have showed, in this work, unusual behavior of solar cell composed of small organic molecules under the influence of thermal annealing at different conditions. This behavior seemed uncommon for polymer solar cells. We try from this work to understand device physics and to locate a relationship between production parameters and performance parameters of the solar cell based on small organic molecules.
\end{abstract}

\section{Introduction}

Organic solar cells have attracted much attention due to their potential in low-cost solar energy harvesting, as well as applications in flexible, light-weight, colorful, and largearea devices [1]. With the discovery of efficient photoinduced electron transfer from a conjugated polymer to fullerene [2], the bulk heterojunction (BHJ) organic solar cell has become one of the most successful device structures developed in the field to date. By simply blending electron donor with electron acceptor (fullerene) in organic solvents, a self-assembling interpenetrating network can be obtained using various coating technologies ranging from laboratoryscale spin-coating or spray-coating to large-scale fabrication technologies such as inkjet printing, doctor blading, gravure, slot-die coating, and flexographic printing. The $\mathrm{BHJ}$ solar cells performed with power conversion efficiency from solar light into electrical energy of up to about $6.1 \%$ [3], and with further progress, the efficiency reached about $6.8 \%$ [1].
To increase knowledge of material characteristics and behavior for photovoltaic applications, new BHJ systems should be studied. For significant improvements in organic solar cell efficiencies, new donor/acceptor combinations may be required to recognize and identify the photovoltaic properties of materials used in solar cells. To construct a new BHJ solar cell using low-molecular-weight compounds such as coumarin dyes, it is better first to illustrate the advantages of this kind of organic dyes. The coumarin dyes have a pronounced light harvesting, and they have been used as light absorbers (a third material) for photovoltaic devices $[4,5]$. The coumarin dyes have been used as photosensitizers in Grätzel-type dye-sensitized solar cells $[6,7]$, as dopants in polymer light emitting diodes (LEDs) $[8,9]$ and as luminescent solar concentrators applied upon solar cells $[10,11]$. Novel iminocoumarin dyes having carboxyl and hydroxyl anchoring groups onto the dyes skeletons have been designed and synthesized by Kandavelu et al. [12] for application of dye-sensitized nanocrystalline $\mathrm{TiO}_{2}$ solar cells. Fullerene 
$\left(\mathrm{C}_{60}\right)$-based donor-acceptor polyads were synthesized by Brites et al. [13], in which $\mathrm{C}_{60}$, as an acceptor material, was covalently linked to some of coumarin dyes, as donor materials, towards practical applications such as photovoltaic devices for solar energy conversion. Coumarin 6 (C6) dye with other organic dyes (oxazine 1 and Nile red) were used by Meixner et al. [14] to manufacture wavelength-selective field-effect phototransistors by employing dye-doped P3HT as a semiconducting layer. Illuminating these transistors with monochromatic light in the range of $400-700 \mathrm{~nm}$ resulted in varying conductivities for certain wavelengths in dependence on the particular dye. This effect is attributed to the photogeneration of excitons on the dye molecules, which are subsequently transferred to the conjugated polymer.

When selecting the donor and acceptor material pair for photovoltaic application, one needs to consider their energy levels. The highest occupied molecular orbital (HOMO) and lowest unoccupied molecular orbital (LUMO) of the material pair need to match in such a way that exciton dissociation (charge separation) will be favored at the interface of the two materials. The conjugated C6 dye in combination with the fullerene derivative $[6,6]$-phenyl- $\mathrm{C}_{61}$ butyric acid methyl ester (PCBM) shows a thermodynamically suitable charge separation at the interface, after light absorption by the sensitized C6 dye. The charge separation in the C6:PCBM combination can occur as a result of decreasing the electron affinity (higher LUMO) and ionization potential (higher HOMO) of C6, as a donor, in comparison with those of PCBM, as an acceptor, as shown in Figure 1 from $[15,16]$. Therefore, the interfacial electric field of the C6:PCBM binary drives charge separation, and the generated electrons are transported by PCBM into the cathode (Al), while the generated holes are transported by $\mathrm{C} 6$ into the anode (indium-tin-oxide (ITO)). Hence, the C6 dye can be used in a new BHJ solar cell for light harvesting and electron donation in combination with PCBM molecules. In a previous work [5], we used the C6 dye as a third material for light harvesting included in the most common binary of the solar cells, which are composed of poly(3-hexylthiophene) (P3HT), as a donor, and PCBM, as an acceptor. The C6 dye in the P3HT:PCBM binary showed a pronounced contribution to optical absorption and photocurrent of the solar cell.

Although the organic dyes have been extensively used in dye-sensitized solar cells, there are few papers $[17,18]$ concerning BHJ organic solar cells based on organic dyes as donor materials. Among those few papers, there are fewer papers, which have investigated thermal annealing [19] and active layer concentration effects on solar cells based on small organic molecules. Thermal annealing is one of the most effective ways to realize high-power conversion efficiency of the organic solar cells, since it results in the improved nanoscale morphology, the increased crystallinity of active layer, and the improved contact to the electron-collecting electrode [20]. The effect of thermal annealing on solar cells composed of small-organic molecules is different from effect of thermal annealing on those composed of polymers. This is because of the difference in the molecular structure of the two materials. Many authors [21-23] stated that the

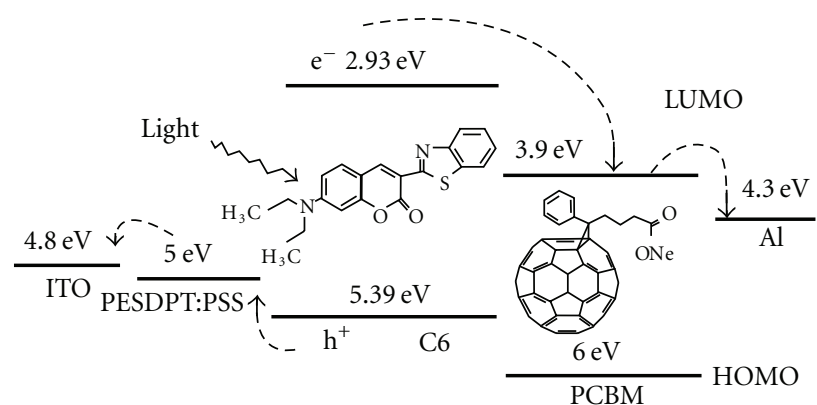

FIGURE 1: Energy-level diagram of C6 dye (from [15]) and the rest components of the solar cell (from [16]) relative to vacuum. The figure shows the chemical structures of C6 and PCBM.

polymers, as an active material in solar cell, gradually influenced under gradual increase in the annealing temperature, during a specific range. This influence appeared as a large redshift in the polymer absorption peak, which indicated high organization in the polymer chains, as a large molecule, under the influence of annealing temperature. While Sakai et al. [19] stated that, the amorphous structure of the alpha-sexithiophen, as a small-organic material, remained after thermal annealing without change in a $\mathrm{BHJ}$ solar cell. This means that, the thermal treatment did not change the structure of the small organic compound, from amorphous to crystalline. These results emphasize that, the effect of thermal annealing on small organic solar cells is different from the effect on polymer solar cells.

There is another important point in the subject of thermal annealing effect on organic solar cells, especially in case of small-organic solar cells. This point has not been taken into account in the previous works, even in the works concerning polymer solar cells. In the previous works, thermal annealing was done either before cathode deposition or after cathode deposition. It is well known that, thermal annealing before cathode deposition induces change in crystal structure of active layer, while thermal annealing after cathode deposition induces the variation in crystal structure and the variation in the contact between active layer and cathode as well. Thermal annealing after cathode deposition is dominant in the previous literatures, but this treatment does not identify and distinguish between variation occurring in crystal structure and that occurring in the contact between active layer and cathode. This means that, someone cannot distinguish which variation is more susceptible to thermal annealing; variation in crystal structure or variation in contact between active layer and cathode. So, we introduce in the present work a solution for this problem. In this regard, thermal annealing is carried out through subsequent two annealing steps: annealing before cathode deposition followed by annealing after cathode deposition. Thermal annealing before cathode deposition is for ensuring and stabilizing the variation in crystal structure of the active layer, which can be detected by atomic force microscopy (AFM) or optical absorption spectroscopy. Then, after stabilizing variation in crystal structure (by annealing before cathode deposition), thermal annealing after cathode deposition is for investigating the variation which occurs in the contact 


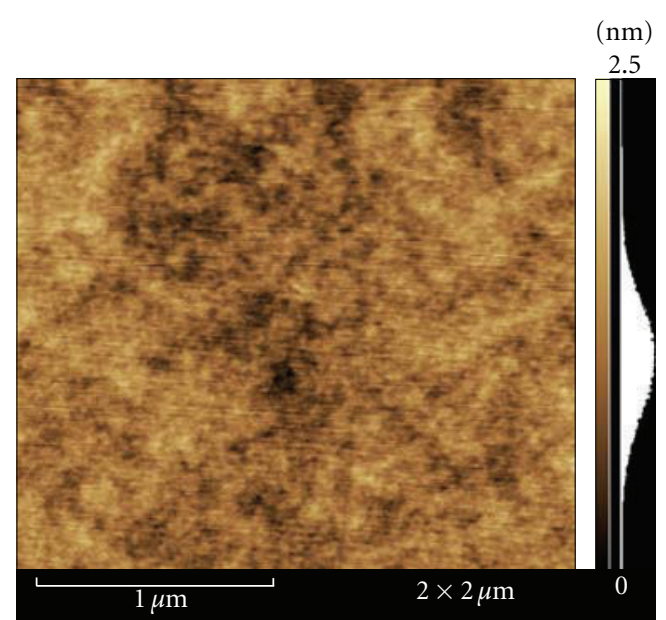

(a)

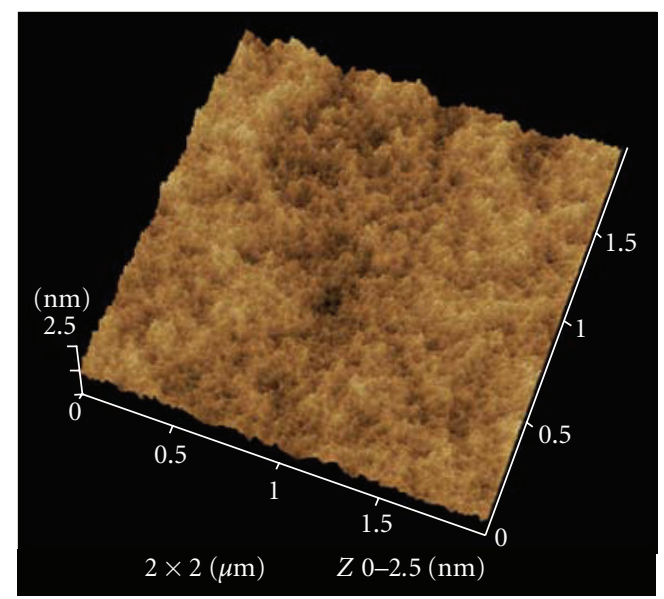

(b)

FIGURE 2: AFM images of C6:PCBM (40:60 weight percentage) blend film spin-coated onto microglass substrate.

between active layer and cathode, which can be detected via photocurrent spectroscopy and/or current density-voltage characteristics measurements of the solar cell.

\section{Results and Discussion}

2.1. Effect of Thermal Annealing. Before talking about effect of thermal annealing on performance of the C6:PCBM solar cell, we prefer, first, to investigate the interpenetrating networks of the C6 dye and PCBM molecules in a BHJ blend. The formation of $\mathrm{BHJ}$ by blending $\mathrm{C} 6$ dye as a donor material with PCBM as an acceptor material and the resulting possible efficient charge separation throughout the C6:PCBM blend are verified through AFM images, as shown in Figure 2.

For understanding C6:PCBM device physics, we investigate the effect of thermal annealing on the performance of this new solar cell. In general, thermal annealing of $\mathrm{BHJ}$ solar cells is carried out either before cathode deposition [24] or after cathode deposition [25]. The purpose of annealing before cathode deposition is for removing any residual solvent and for enhancing crystal structure of the active layer
[26], while thermal annealing after cathode deposition is for improving the contact between active layer and cathode, and therefore charge collection at the cathode is improved [20]. In many literatures, annealing after cathode deposition is dominant for enhancing crystal structure of active layer and, also, for improving the contact between active layer and cathode. However, if the annealing after cathode deposition may damage the contact between active layer and cathode, for some reason, the enhancement in crystal structure of the active layer, gained by annealing, may not be distinguished. In addition, if the annealing after cathode deposition may impair crystal structure of the active layer, the enhancement, gained by annealing, in the contact between active layer and cathode may not be distinguished. So, we try in this work to illustrate and differentiate between thermal annealing affecting crystal structure of the active layer blend and thermal annealing affecting the contact between active layer and cathode.

First, the effect of thermal annealing on crystal structure of the active layer is investigated through the effect of thermal annealing before $\mathrm{Al}$ deposition on the optical absorption of the C6:PCBM blend film. The optical absorption spectroscopy is an efficient tool for detecting the organization of the molecules in crystalline domains as stated by Vanlaeke et al. [22]. Thermal treatment of the C6:PCBM blend film is carried out at different temperatures in the range of 40$140^{\circ} \mathrm{C}$ and at different annealing times (5 or $10 \mathrm{~min}$ ) in a glove box under nitrogen atmosphere. Figure 3 shows optical absorption spectra of the C6:PCBM blend films before and after thermal annealing (before Al deposition) in the wavelength range of $250-800 \mathrm{~nm}$. Before thermal treatment, the C6 dye in the C6:PCBM blend film gives an eminent absorption peak at a wavelength of $450 \mathrm{~nm}$. After thermal annealing at different temperatures beginning from $40^{\circ} \mathrm{C}$ up to $140^{\circ} \mathrm{C}$, the absorption peak of the $\mathrm{C} 6$ in the blend film slightly redshifts to $454 \mathrm{~nm}$ under different annealing times. The redshift of the C6 absorption peak caused by thermal annealing is an indication of improvement in conjugation length of the C6 molecules in the blend [27]. Thermal annealing improves conjugation length of both polymers as well as small organic molecules which are much more likely to crystallize than the polymer in dye/polymer blend photovoltaic cells, as stated by Dittmer et al. [28]. However the improvement in the conjugation length of the C6 dye is small as a result of small molecular weight and short conjugation of the small molecule. The development of a vibronic structure by thermal annealing can also be seen in Figure 3 (as improvement in shoulder peak around $478 \mathrm{~nm}$ ), which is generally explained in semiconducting polymers by a higher crystallization or ordering of intrachain interactions [29]. The improvement in conjugation length means that the alternation of single-double bonds between carbon atoms through C6 molecules increases, and, therefore, the $\pi-\pi^{*}$ transition shifts to a lower energy. This tends to a decrease in the energy gap of the C6 dye in the C6:PCBM blend by thermal annealing. Therefore, the C6 absorbs a larger amount of light photons, which have lower energy, and, consequently, the generation of charge carriers increases in the solar cell active layer. As shown in Figure 3, the 


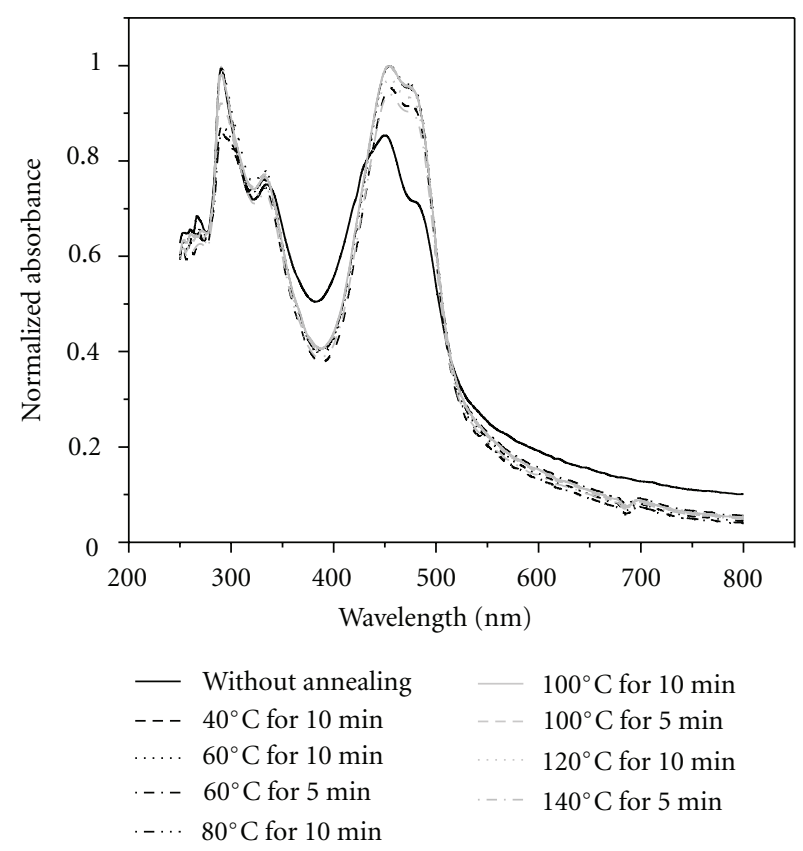

Figure 3: Optical absorbance of C6:PCBM blend film before and after thermal annealing at different temperatures and annealing times.

contribution of PCBM molecules in the absorption of the active layer blend occurs at a wavelength of approximately $332 \mathrm{~nm}$. After thermal annealing the peak at $332 \mathrm{~nm}$ does not show any change at any annealing conditions.

It is obviously observed from Figure 3 that, the effect of thermal annealing on the C6:PCBM blend film, which results in improving conjugation length of the C6 dye in the blend, occurs at the lowest annealing temperature of the investigated range. This is because the C6 dye is a small organic molecule, which has small molecular weight and short conjugation. So, the lowest annealing temperature in the scanned range is sufficient to affect this small molecule. As shown in Figure 3, with increasing annealing temperature from 40 to $140^{\circ} \mathrm{C}$ at various annealing times the optical absorption of the C6:PCBM blend film does not change. This indicates that the induced structure of the C6:PCBM blend film by thermal annealing attains to a steady state under lower annealing temperature and is not disturbed by further increase in the annealing temperature, up to $140^{\circ} \mathrm{C}$. As an indication, Kim et al. [23] stated that, there was no distinct variation in the absorption spectra, when annealing temperature upon active layer composed of poly (3-hexylthiophene) ( $\mathrm{P} 3 \mathrm{HT}): \mathrm{PCBM}$ blend rose above $100^{\circ} \mathrm{C}$, and the spectrum at $180^{\circ} \mathrm{C}$ was very similar to that of $150^{\circ} \mathrm{C}$.

Second, the effect of thermal annealing on the contact between C6:PCBM active layer and $\mathrm{Al}$ electrode is investigated through measurement of photocurrent and performance parameters of the solar cells. Thermal treatment, in this case, is carried out through subsequent two annealing steps; first annealing step, which is carried out before $\mathrm{Al}$ deposition at $100^{\circ} \mathrm{C}$ for $10 \mathrm{~min}$ (preannealing), and second annealing step, which is carried out after $\mathrm{Al}$ deposition at various temperatures in the range of $50-160^{\circ} \mathrm{C}$ for $4 \mathrm{~min}$

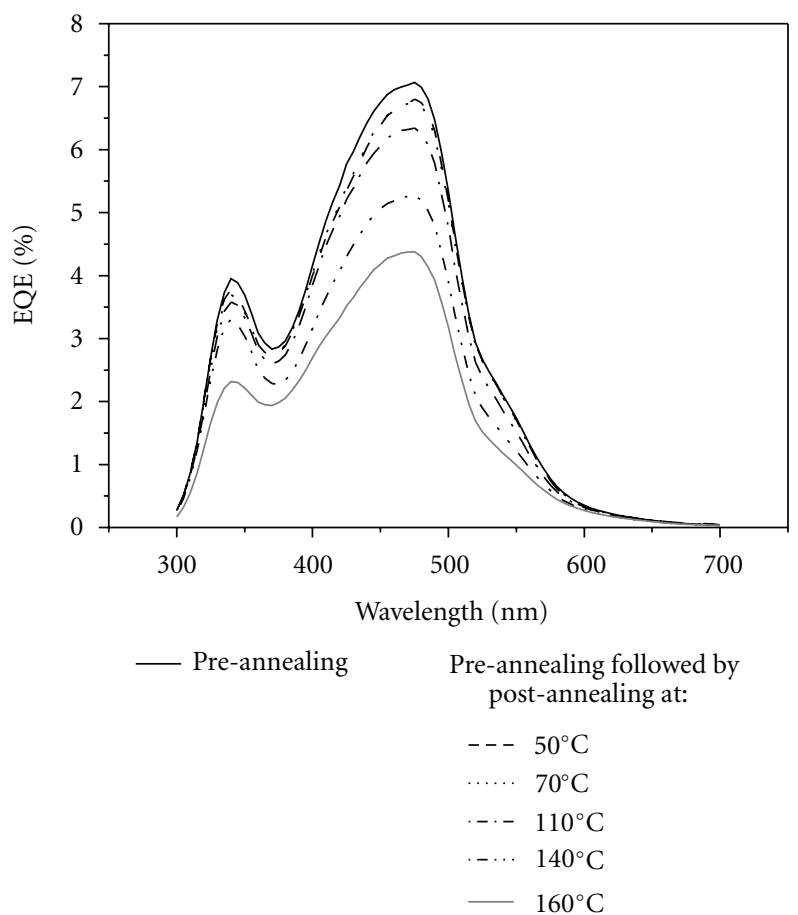

FIGURE 4: EQE spectra of the ITO/PEDOT:PSS/C6:PCBM/Al solar cell under thermal treatment before $\mathrm{Al}$ deposition at $100^{\circ} \mathrm{C}$ for $10 \mathrm{~min}$ (preannealing) and under subsequent treatments; preannealing (at $100^{\circ} \mathrm{C}$ for $10 \mathrm{~min}$ ) followed by annealing after $\mathrm{Al}$ deposition (postannealing) at different temperatures.

(postannealing) in a glove box under nitrogen atmosphere. In this case, the preannealing step stabilizes the structure of the active layer. Therefore, postannealing step governs the variation in the contact between C6:PCBM active layer and $\mathrm{Al}$ electrode. There is no reason for specifying the $100^{\circ} \mathrm{C}$ for $10 \mathrm{~min}$ as conditions for preannealing step, whereas the structure of the C6:PCBM active layer is secured under the whole investigated preannealing temperature range (40$140^{\circ} \mathrm{C}$ ) without change, as shown from Figure 3.

Figure 4 shows the external quantum efficiency (EQE) spectra of the ITO/poly(3,4-ethylene dioxythiophene)blend-poly(styrene sulfonate) (PEDOT:PSS)/C6:PCBM/Al solar cell under preannealing alone and under subsequent two treatments; preannealing (at $100^{\circ} \mathrm{C}$ for $10 \mathrm{~min}$ ) and postannealing (at different temperatures in the range of $50-160^{\circ} \mathrm{C}$ for $4 \mathrm{~min}$ ) in the wavelength range from 300 to $700 \mathrm{~nm}$. Without thermal annealing, no working device is obtained. The EQE maximum peak of the C6:PCBM active layer at about $475 \mathrm{~nm}$ relates to contribution of the C6 dye to the photocurrent, while the dye absorbs light at about $454 \mathrm{~nm}$, as shown in Figure 3. The EQE spectra of the investigated solar cell show a contribution of PCBM to the photocurrent at a wavelength of approximately $340 \mathrm{~nm}$, while the PCBM absorbs light at about $332 \mathrm{~nm}$. As shown in Figure 4, exclusive preannealing of the $\mathrm{C} 6$ :PCBM active layer produces a $7.1 \%$ as contribution of $\mathrm{C} 6$ dye to the photocurrent, while postannealing at $50^{\circ} \mathrm{C}$ preceded by preannealing reduces the contribution of the C6 dye to $6.8 \%$. By gradual increase in postannealing temperature, the contribution of 
the C6 dye to the photocurrent gradually decreases to reach $4.4 \%$ at $160^{\circ} \mathrm{C}$. Although the structure of the C6 dye in the blend is secured by preannealing step, the decrease in contribution of the C6 dye to EQE spectra is attributed to deterioration in the interface between C6:PCBM active layer and $\mathrm{Al}$ electrode. This is because the damage in the contact between active layer and cathode reduces charge carrier transport and collection at the electrode and therefore reduces the photocurrent and performance parameters of the organic solar cell.

Current density/voltage $(J / V)$ characteristics of the devices under dark and under AM1.5 G white light illumination $\left(100 \mathrm{~mW} / \mathrm{cm}^{2}\right)$ are shown in Figure 5. Figures 6 and 7 show the variation in performance parameters, that is, open circuit voltage $\left(V_{\mathrm{OC}}\right)$, short-circuit current density $\left(J_{\mathrm{SC}}\right)$, fill factor $(\mathrm{FF})$, and power conversion efficiency $(\mathrm{PCE})$, of the solar cell under preannealing and under preannealing followed by postannealing with increasing postannealing temperature from 50 to $160^{\circ} \mathrm{C}$. As shown in these figures, the solar cell which is only preannealed has the best performance parameters in comparison with the solar cell which is postannealed during temperature range of $50-160^{\circ} \mathrm{C}$ after securing the internal structure of blend film by preannealing treatment firstly. It is observed from Figures 6 and 7 that all performance parameters of the C6:PCBM solar cell almost decrease with increasing postannealing temperature from 50 to $160^{\circ} \mathrm{C}$. In general perception, the $V_{\mathrm{OC}}$ is determined by the energy difference between HOMO of the donor and LUMO of the acceptor [16]. However, the decrease in the $V_{O C}$ may be a result of energy level realignment at C6:PCBM/Al interface due to postthermal annealing, as stated by Zhao et al. [20]. Sakai et al. [19], also, guessed that the variation in the contact between active layer and electrode, due to postthermal annealing, probably influenced the $V_{\mathrm{OC}}$ value. The decrease in FF, shown in Figure 6, is an indication of increasing series resistance, which is produced in the solar cell due to the damage in the interface between C6:PCBM active layer and $\mathrm{Al}$ electrode, as a result of postannealing. The increase in $V_{\mathrm{OC}}$ at higher postannealing temperatures $\left(140\right.$ and $\left.160^{\circ} \mathrm{C}\right)$ may be attributed to a decrease in ohmic contact at the interface between PCBM and $\mathrm{Al}$ electrode. The change in ohmic contact at the interface may be a result of energy level realignment due to postthermal annealing as stated by Zhao et al. [20]. The ohmic contact is considered as a large series resistance, and the change in this series resistance has strong impact on the FF of the solar cell. Therefore, the observed increase in the $\mathrm{FF}$ at higher postannealing temperatures is an indication of the decreasing ohmic contact between PCBM and $\mathrm{Al}$ electrode.

The $J_{S C}$ has direct dependence on the charge carrier transport and electron collection at the cathode in the solar cell. The generated electrons in the active layer transfer and collect at the cathode due to influence of the cathode work function. Therefore, the decrease in the $J_{\mathrm{SC}}$, as shown in Figure 7, with increasing postannealing temperature is attributed to disability of generated electrons in the active layer to transfer and collect at $\mathrm{Al}$ electrode due to damage in the interface between active layer and electrode. The cause of damage in the contact between C6:PCBM active

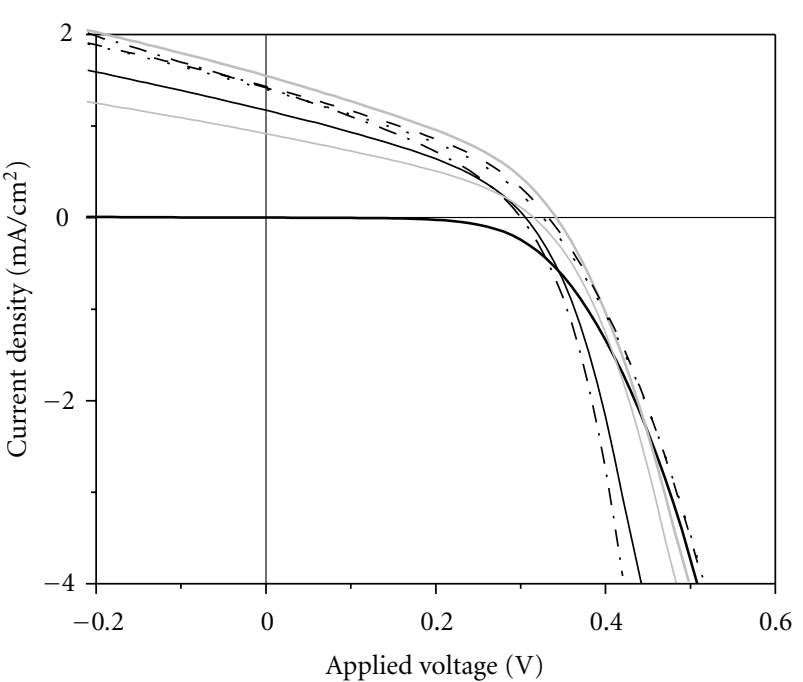

Pre-annealing under dark
Pre-annealing under illumination $\begin{array}{r}\text { Pre-annealing with } \\ \text { post-annealing at: } \\ ---50^{\circ} \mathrm{C} \\ \cdots \cdots 70^{\circ} \mathrm{C} \\ --110^{\circ} \mathrm{C} \\ -\cdots 140^{\circ} \mathrm{C} \\ -160^{\circ} \mathrm{C}\end{array}$

Figure 5: $J / V$ characteristics of the ITO/PEDOT:PSS/C6:PCBM/Al solar cell under thermal treatment conditions as those described in Figure 4.

layer and $\mathrm{Al}$ electrode (due to postthermal annealing) is not completely clear. In all probabilities, the C6 small organic dye is responsible for this damage, but the damage mechanism is not totally understood. However, this damage was seen by the naked eye as small bubbles or blisters formed after thermal annealing on the surface of the $\mathrm{Al}$ electrode. It was observed that these bubbles were increased in their size and density over active layer surface by increasing postannealing temperature. These small bubbles were not found in the preannealed solar cell.

From previous observations and discussion we can conclude that, the internal structure of the C6:PCBM active layer is induced by thermal annealing before $\mathrm{Al}$ deposition at low annealing temperature and remains without change up to $140^{\circ} \mathrm{C}$, while the contact between active layer and $\mathrm{Al}$ electrode is destroyed by thermal annealing after $\mathrm{Al}$ deposition at low annealing temperature and up to $160^{\circ} \mathrm{C}$. As a more elaborate indication of these results, optical absorption spectra of the C6:PCBM blend film under subsequent two annealing steps; annealing at $100^{\circ} \mathrm{C}$ for $10 \mathrm{~min}$ (preannealing) followed by annealing at various temperatures in the range of 50 $160^{\circ} \mathrm{C}$ for $4 \mathrm{~min}$ (postannealing), (spectra not shown here) do not show any variation in the absorption peaks of both C6 dye and PCBM. This means that, postannealing step does not alter the internal structure of the C6:PCBM blend film, which stabilizes, firstly, by preannealing treatment. Therefore, the deterioration in the measured photocurrent and performance parameters of the solar cell is caused by thermal annealing after $\mathrm{Al}$ deposition. 


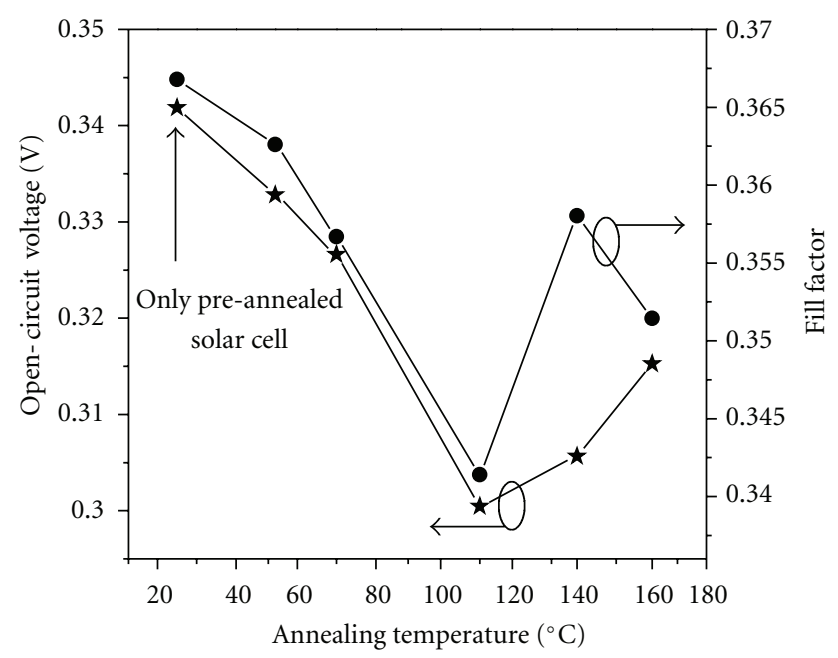

FIgURE 6: Variation in $V_{\mathrm{OC}}$ and FF with annealing temperature of the ITO/PEDOT:PSS/C6:PCBM/Al solar cell.

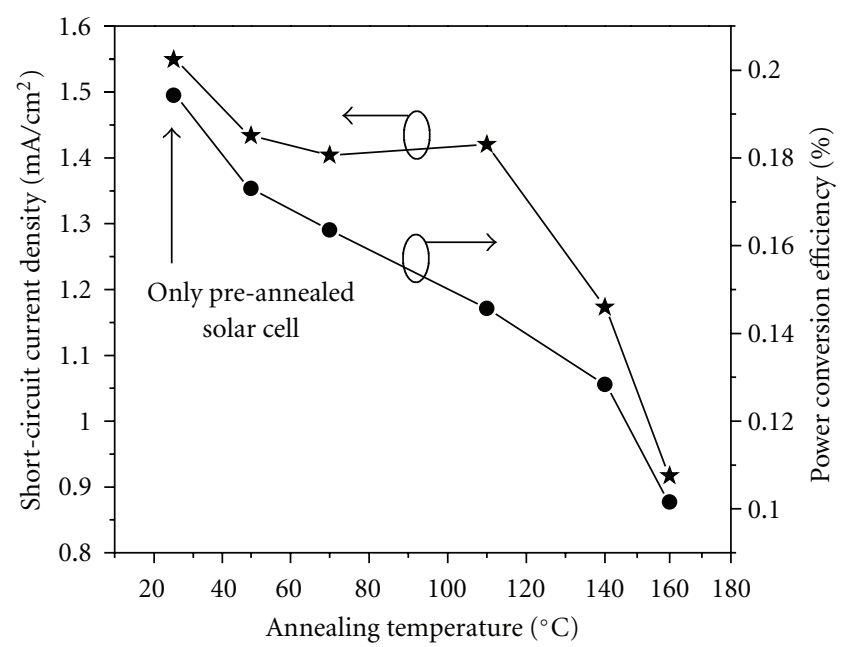

FIGURE 7: Variation in $J_{S C}$ and PCE with annealing temperature of the ITO/PEDOT:PSS/C6:PCBM/Al solar cell.

2.2. Effect of Blend Concentration. After interesting behavior of the BHJ C6:PCBM solar cell under the influence of thermal annealing in last section, it is worthy now to investigate the behavior of this new combination under variation of blend concentration, for further understanding of new $\mathrm{BHJ}$ solar cell. In this investigation, the C6:PCBM blend concentration varies as $10,20,30$, and $40 \mathrm{mg} / \mathrm{mL}$, and the optical absorption spectroscopy, photocurrent spectroscopy, and $J / V$ characteristics measurement are carried out and discussed as below.

Optical absorption of the C6:PCBM blend films, spincoated onto ITO-glass substrates, as a function of blend concentration is shown in Figure 8 in the wavelength range of $250-600 \mathrm{~nm}$. As shown from Figure 8, the absorption of the C6:PCBM blend film gradually increases with gradual increase in the blend concentration. The increase in optical absorption is attributed to increase in the amounts

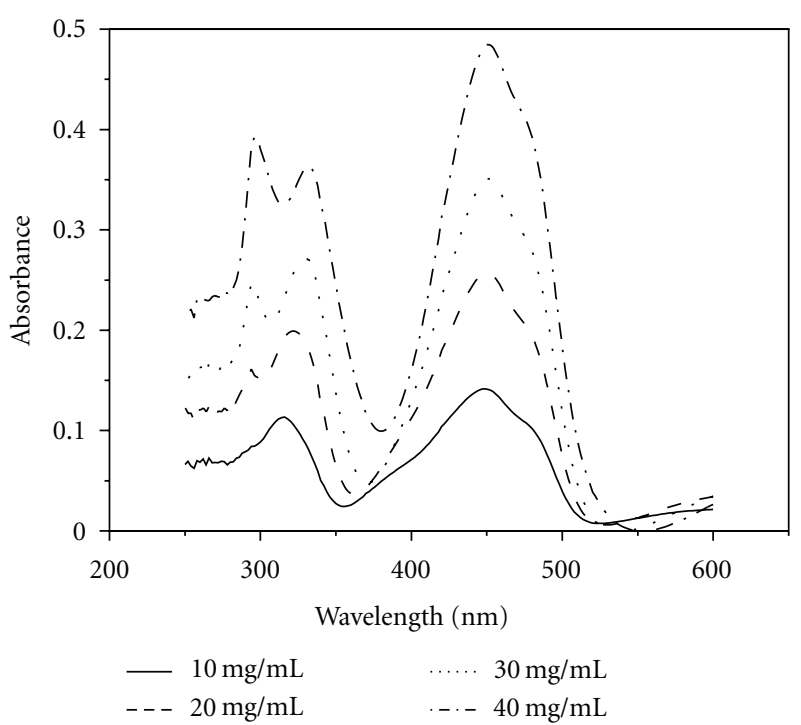

Figure 8: Optical absorbance of C6:PCBM blend film at different blend concentrations.

of absorber material in active layer by increasing their concentration in the films. In this case, the active layer captures large amounts of light photons from incident light. The intensity of shoulder peak around $476 \mathrm{~nm}$ is less than that of C6:PCBM blend film spin-coated onto microglass substrates, as shown in Figure 3. This observation may be attributed to vibronic structure of the C6 molecules, which is influenced by interaction between electrons on the surface of ITO-metal electrode and active layer. It is observed from Figure 8 that, the absorption peaks of both $\mathrm{C} 6$ and PCBM gradually redshift with increasing C6:PCBM blend concentration. The absorption peaks of the C6 and PCBM in the blend having the concentration of $10 \mathrm{mg} / \mathrm{mL}$ locate at 448 and $316 \mathrm{~nm}$, respectively. With increasing C6:PCBM blend concentration up to $40 \mathrm{mg} / \mathrm{mL}$, the absorption peaks of the C6 and PCBM redshift to 452 and $332 \mathrm{~nm}$, respectively. The observed redshift in the absorption of the C6:PCBM blend film at constant annealing conditions is attributed to increase in the conjugation length of both C6 and PCBM molecules in the active layer blend, as a result of increasing blend concentration. Hoppe et al. [30] revealed that the fullerene cluster size and the average film thickness were increased with higher concentration of the MDMO-PPV:PCBM solar cell.

Figure 9 shows EQE spectra of the ITO/PEDOT:PSS/ C6:PCBM/Al solar cells under variation in active layer blend concentration in the wavelength range of $300-700 \mathrm{~nm}$. As shown in this figure, the contribution of the C6 dye to the photocurrent increases at a wavelength of $470 \mathrm{~nm}$ from $2.9 \%$ to $8.1 \%$ after increasing C6:PCBM blend concentration from 10 to $30 \mathrm{mg} / \mathrm{mL}$. Further increase in the blend concentration up to $40 \mathrm{mg} / \mathrm{mL}$ reduces the contribution of the C6 dye to $6.1 \%$ at $445 \mathrm{~nm}$. In organic cells, the EQE depends on optical absorption, exciton diffusion, exciton dissociation into free carriers, charge transport, and charge collection at electrodes. So, the increase in the photocurrent (from 2.9 to 


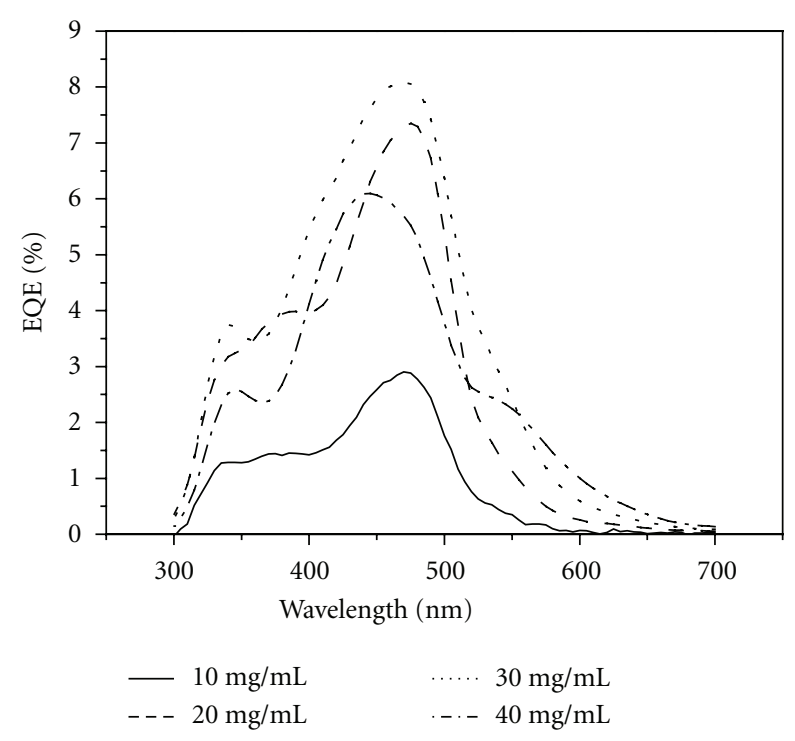

FIGURE 9: EQE spectra of the ITO/PEDOT:PSS/C6:PCBM/Al solar cell at different C6:PCBM blend concentrations.

8.1\%) with increasing C6:PCBM blend concentration (from 10 to $30 \mathrm{mg} / \mathrm{mL}$ ) is attributed to two main reasons. First, the increase in the C6:PCBM blend concentration increases the optical absorption of the active layer, as shown from Figure 8 . The increase in light harvesting by solar cell active layer tends to increase the generated charge carriers and photocurrent. Second, the increase in the C6:PCBM blend concentration increases the conjugation length of the blend film (indicated from the redshift of C6:PCBM absorption peak in Figure 8), which tends to improve charge carrier transport and therefore tends to improve the photocurrent and performance parameters of the solar cell. In general, organic semiconductors are materials exhibiting low mobilities, ranging between $\approx 10^{-5}$ to $10^{0} \mathrm{~cm}^{2} / \mathrm{Vs}$ [31]. This directly limits active layer thickness of organic photovoltaic devices. Beyond a certain thickness, charge carriers will not reach the electrodes before recombination [32]. Therefore, the decrease in the photocurrent, observed in Figure 9, of the C6:PCBM solar cell having blend concentration of $40 \mathrm{mg} / \mathrm{mL}$ is attributed to accumulation of active layer components at higher concentrations, which restricts exciton diffusion and charge carrier transfer into respective electrodes and therefore reduces the photocurrent and performance parameters of the solar cell. Although the C6:PCBM blend having the concentration of $40 \mathrm{mg} / \mathrm{mL}$ can produce excess of excitons as a result of its high ability for light harvesting, most of these excitons do not dissociate to charge carriers due to large exciton diffusion length, which must be routed by these excitons to dissociate at the interface between C6 and PCBM. Therefore, the charge carrier generation and, consequently, the photocurrent and performance parameters decrease in the solar cell.

After analysis of $J / V$ characteristics (shown in Figure 10), one can easily detect that, the performance parameters of the ITO/PEDOT:PSS/C6:PCBM/Al solar cells almost have the same behavior of the EQE spectra under variation of

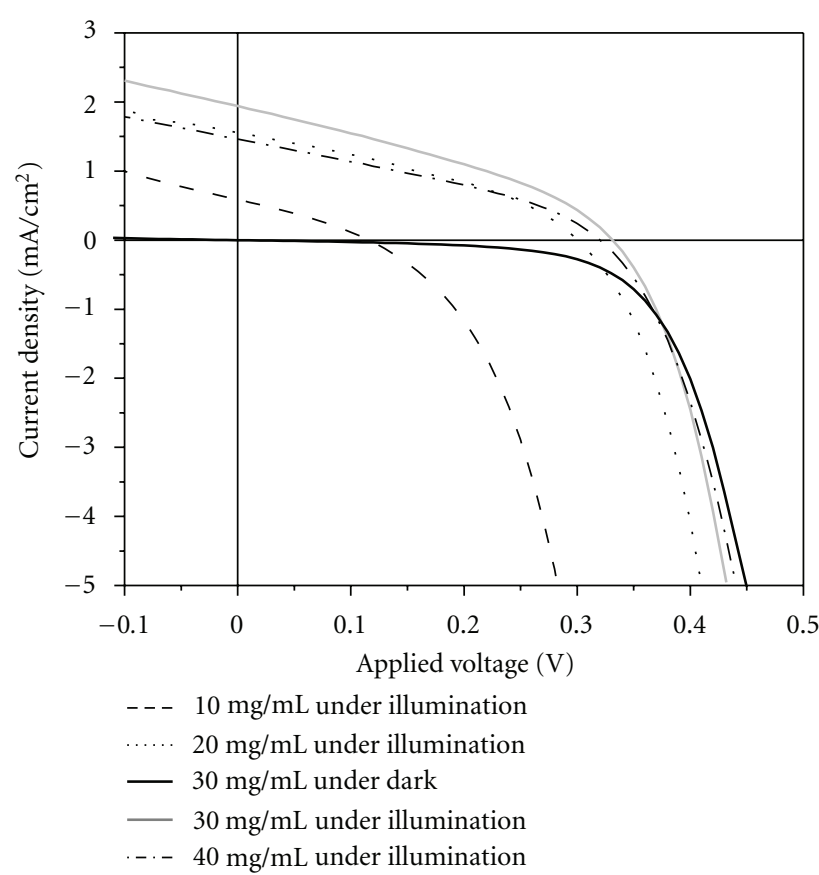

Figure 10: $J / V$ characteristics of the ITO/PEDOT:PSS/C6:PCBM/ $\mathrm{Al}$ solar cell at different $\mathrm{C6}$ :PCBM blend concentrations.

the C6:PCBM blend concentration, as shown in Figures 11 and 12. Figure 11 shows the variation in $V_{\mathrm{OC}}$ and FF, while Figure 12 shows the variation in $J_{\mathrm{SC}}$ and PCE as a function of C6:PCBM blend concentration from 10 to $40 \mathrm{mg} / \mathrm{mL}$. The variation in the $J_{S C}$ and, consequently, PCE with C6:PCBM blend concentration agrees with the variation in the EQE with blend concentration, for the same reasons, whereas the light harvesting, exciton diffusion and dissociation, and charge carrier transport are the factors that govern the variation of $J_{\mathrm{SC}}$ with C6:PCBM blend concentration. At $30 \mathrm{mg} / \mathrm{mL}$ blend concentration, the film absorbs reasonable amounts of light photons and, in the same time, does not obstruct neither exciton diffusion and dissociation nor charge carrier transfer into electrodes. Therefore, the C6:PCBM solar cell with the blend concentration of $30 \mathrm{mg} / \mathrm{mL}$ shows the highest value of the $J_{\mathrm{SC}}$ of the investigated solar cells. The variation in the $V_{\mathrm{OC}}$ with C6:PCBM blend concentration follows the variation in the EQE and $J_{\mathrm{SC}}$ with blend concentration, although the difference between HOMO of the C6 and LUMO of the PCBM does not change under variation of the C6:PCBM blend concentration. The observed variation in the $\mathrm{FF}$ strongly relates to the influence of series resistance in the solar cell. As shown in Figure 11, the increase in blend concentration up to $20 \mathrm{mg} / \mathrm{mL}$ increases the FF up to 0.36 , while further increase in the blend concentration up to $40 \mathrm{mg} / \mathrm{mL}$ reduces the FF to 0.34 . The small observed increase in the FF may be attributed to increase in the charge carrier transport due to increase in the conjugation length and size of PCBM clusters with increasing blend concentration. The improved PCBM clusters in the C6:PCBM blend efficiently transport the photogenerated mobile electrons by means of percolated pathways to the respective electrode. The 
small decrease in the FF may be attributed to small increase in the series resistance due to increase in C6 and PCBM aggregates at higher concentrations. These aggregates reduce charge carrier mobility, and therefore, the FF decreases in the active layer. From Figures 11 and 12 in addition to Figure 9, we can indicate that the best blend concentration in the new C6:PCBM solar cell is the concentration of $30 \mathrm{mg} / \mathrm{mL}$. The solar cell which has $30 \mathrm{mg} / \mathrm{mL}$, as an active layer concentration, produces $0.33 \mathrm{~V}$ as a $V_{\mathrm{OC}}, 0.34$ as a FF, $1.9 \mathrm{~mA} / \mathrm{cm}^{2}$ as a $J_{\mathrm{SC}}$, and $0.22 \%$ as a PCE.

\section{Experimental Section}

3.1. Materials and Solutions. The C6 or [3-(2-benzothiazolyl)-7-(diethylamino)coumarin] conjugated dye (99\%, Sigma-Aldrich) and PCBM (99.2\%, Frontier Carbon Corporation, Japan) were used without further purification. The C6:PCBM blend solutions with the composition of $40: 60$ weight percentage were prepared by dissolving the two compounds (C6 dye and PCBM) in 1,2-dichlorobenzene (Tokyo Chemical Industry Co. Ltd., Japan) with varying blend concentration as $10,20,30$, and $40 \mathrm{mg} / \mathrm{mL}$. The solutions were vigorously stirred for more than $24 \mathrm{~h}$ at room temperature under nitrogen atmosphere in a glove box to maximize mixing while avoiding touching the vial cap.

3.2. Film and Device Fabrication. For optical absorption measurement, the C6:PCBM blend films with different concentrations were prepared by spin-coating the solutions onto clean ITO-glass substrates. For solar cell fabrication, the ITO-glass substrates $(\sim 10 \Omega / \square)$ were sequentially cleaned in an ultrasonic bath using acetone (twice) and methanol (once), rinsed with deionized water, and finally dried in flowing nitrogen. To increase the work function of the ITO electrode and to improve the electrical connection between ITO electrode and organic active layer, a layer of PEDOT:PSS was spin-coated $(2500 \mathrm{rpm})$ onto the ITO-glass substrates in air and dried using a digitally controlled hotplate at $100^{\circ} \mathrm{C}$ for $10 \mathrm{~min}$ under nitrogen atmosphere in a glove box. On top of insoluble PEDOT:PSS layer, the C6:PCBM blend solutions with different concentrations were spin-coated (1000 rpm) under nitrogen atmosphere. An approximately 100-nm-thick $\mathrm{Al}$ electrode was thermally deposited onto the active layer using a vacuum deposition system at a pressure of about 3 $\times 10^{-4} \mathrm{~Pa}$ through a shadow mask to obtain 25 identical cells on one device with an active area of $3 \times 3 \mathrm{~mm}^{2}$. The thermal annealing of the solar cells was carried out before and after $\mathrm{Al}$ deposition under nitrogen atmosphere in a glove box. The use of nitrogen atmosphere during thermal treatment is for suppressing the formation of carbonyl defects that reduces the conjugation length of the active layer blend and thus lowers the electrical conductivity of the active layer when oxidized.

3.3. Measurements. The optical absorption spectroscopy of C6:PCBM blend films with varying annealing temperature and blend concentration was carried out using a JASCO

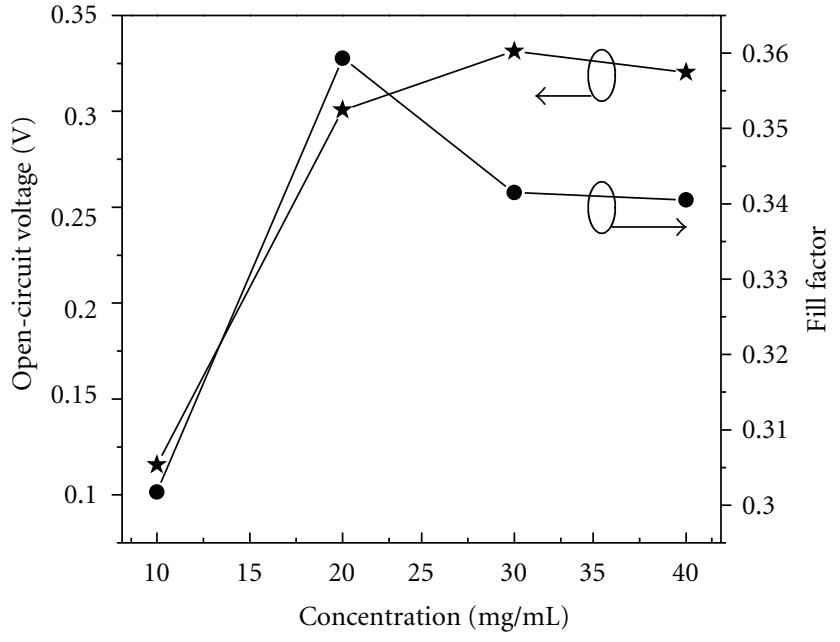

Figure 11: Variation in $V_{\mathrm{OC}}$ and FF with C6:PCBM blend concentration of the ITO/PEDOT:PSS/C6:PCBM/Al solar cell.

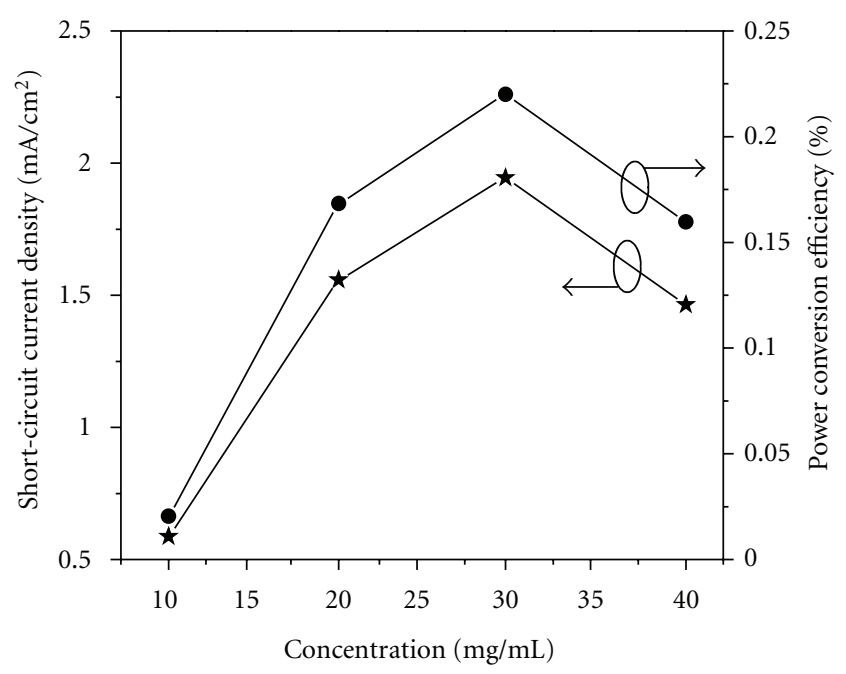

Figure 12: Variation in $J_{S C}$ and PCE with C6:PCBM blend concentration of the ITO/PEDOT:PSS/C6:PCBM/Al solar cell.

V-570 ultraviolet/visible/near-infrared (UV/vis/NIR) spectrophotometer with incident light towards the coated side of the films. The external quantum efficiency measurement was performed for the devices with varying annealing temperature and active layer concentration using a halogen lamp and a monochromator. The $J / V$ characteristics of the devices under white light illumination were determined using standard solar irradiation of $100 \mathrm{~mW} / \mathrm{cm}^{2}$ (AM1.5) with a JASCO CEP-25BX spectrophotometer $J / V$ measurement setup with a xenon lamp as the light source and a computer-controlled voltage-current source meter (Keithley 238) at $25^{\circ} \mathrm{C}$ under nitrogen atmosphere. The $J / V$ characteristics were determined for many cells in one device, and we considered the performance parameters of the best solar cell in that device. All measurements were performed 
soon after preparation of the devices to avoid any change in the photoelectric properties caused by aging. The external quantum efficiency and performance parameter values in this work did not consider the device degradation caused by light and air.

\section{Conclusions}

For understanding and improving new C6:PCBM combination as a small organic solar cell, we have studied effect of thermal annealing and blend concentration on light harvesting, photocurrent, and performance parameters of the solar cell. Thermal annealing in this work was carried out for specifying and differentiating between annealing affecting internal structure of the C6:PCBM blend film, through treatment before $\mathrm{Al}$ deposition at $100^{\circ} \mathrm{C}$ for $10 \mathrm{~min}$, and annealing affecting the contact between C6:PCBM active layer and $\mathrm{Al}$ electrode, through consequent two annealing steps; annealing after $\mathrm{Al}$ deposition at various temperatures in the range of $50-160^{\circ} \mathrm{C}$ for 4 min preceded by annealing before $\mathrm{Al}$ deposition at $100^{\circ} \mathrm{C}$ for $10 \mathrm{~min}$. By optical absorption spectroscopy, we detected a redshift in C6 absorption peak at $40^{\circ} \mathrm{C}$, as indication of increasing conjugation length of the $\mathrm{C} 6$ dye in the blend. The internal structure of the C6:PCBM blend film remained without change under gradual increase in the annealing temperature up to $140^{\circ} \mathrm{C}$. The deterioration in the contact between C6:PCBM active layer and $\mathrm{Al}$ electrode, as a result of thermal annealing after $\mathrm{Al}$ deposition in the temperature range of $50-160^{\circ} \mathrm{C}$ preceded by annealing before $\mathrm{Al}$ deposition (for stabilizing and insuring the internal structure of the active layer blend at $100^{\circ} \mathrm{C}$ for $10 \mathrm{~min}$ ), was observed through the decrease in the photocurrent and performance parameters of the solar cell. Therefore, the best thermal annealing conditions for the C6:PCBM as a small organic solar cell was the annealing only before $\mathrm{Al}$ deposition in the temperature range of $40-140^{\circ} \mathrm{C}$ for either 5 or $10 \mathrm{~min}$. We showed in this paper that, the effect of thermal annealing on the solar cells composed of small organic molecules was different from effect of thermal annealing on those composed of polymers, as commonly stated in previous literatures. The increase in the C6:PCBM blend concentration showed an increase in the conjugation length accompanied by an increase in the optical absorption of the blend film, which were the reasons for improving charge carrier generation and transfer and therefore increasing the photocurrent and device performance parameters of the solar cell. The reduction in the photocurrent and performance parameters of the C6:PCBM solar cell, due to further increase in the blend concentration, was attributed to reduced mobility of charge carriers, as a result of increase in the aggregation of the materials in the active layer.

\section{Acknowledgment}

Y. A. M. Ismail acknowledges the Egyptian people and government for supporting this work.

\section{References}

[1] H. Y. Chen, J. Hou, S. Zhang et al., "Polymer solar cells with enhanced open-circuit voltage and efficiency," Nature Photonics, vol. 3, no. 11, pp. 649-653, 2009.

[2] N. S. Sariciftci, L. Smilowitz, A. J. Heeger, and F. Wudl, "Photoinduced electron transfer from a conducting polymer to buckminsterfullerene," Science, vol. 258, no. 5087, pp. 14741476, 1992.

[3] S. H. Park, A. Roy, S. Beaupré et al., "Bulk heterojunction solar cells with internal quantum efficiency approaching 100\%," Nature Photonics, vol. 3, no. 5, pp. 297-303, 2009.

[4] X. Jiang Jr., W. F. Burgoyne, and L. M. Robeson, "Sequestration of electroactive materials in a high $\mathrm{T}_{\mathrm{g}}$, insulating polymer matrix for optoelectronic applications-part 2. Photovoltaic devices," Polymer, vol. 47, no. 11, pp. 4124-4131, 2006.

[5] Y. A. M. Ismail, T. Soga, and T. Jimbo, "The contribution of coumarin 6 in light harvesting and photocurrent of P3HT:PCBM bulk heterojunction solar cell," Solar Energy Materials and Solar Cells, vol. 94, no. 8, pp. 1406-1411, 2010.

[6] K. Hara, T. Sato, R. Katoh et al., "Molecular design of coumarin dyes for efficient dye-sensitized solar cells," Journal of Physical Chemistry B, vol. 107, no. 2, pp. 597-606, 2003.

[7] K. Hara, M. Kurashige, Y. Dan-Oh et al., "Design of new coumarin dyes having thiophene moieties for highly efficient organic-dye-sensitized solar cells," New Journal of Chemistry, vol. 27, no. 5, pp. 783-785, 2003.

[8] A. Montali, A. R. A. Palmans, J. Bras et al., "Depolarizing energy transfer in photoluminescent polymer blends," Synthetic Metals, vol. 115, no. 1, pp. 41-45, 2000.

[9] Y. Takahashi, A. Maeda, K. Kojima, and K. Uchida, "Luminescence of dyes doped in a sol-gel coating film," Journal of Luminescence, vol. 87, pp. 767-769, 2000.

[10] A. F. Mansour, H. M. A. Killa, S. Abd El-Wanees, and M. Y. El-Sayed, "Laser dyes doped with poly(ST-Co-MMA) as fluorescent solar collectors and their field performance," Polymer Testing, vol. 24, no. 4, pp. 519-525, 2005.

[11] A. F. Mansour, "Photostability and optical parameters of copolymer styrene/MMA as a matrix for the dyes used in fluorescent solar collectors," Polymer Testing, vol. 23, no. 3, pp. 247-252, 2004.

[12] V. Kandavelu, H. S. Huang, J. L. Jian, T. C. K. Yang, K. L. Wang, and S. T. Huang, "Novel iminocoumarin dyes as photosensitizers for dye-sensitized solar cell," Solar Energy, vol. 83, no. 4, pp. 574-581, 2009.

[13] M. J. Brites, C. Santos, S. Nascimento, B. Gigante, and M. Berberan-Santos, "Synthesis of [60] fullerene-coumarin polyads," Tetrahedron Letters, vol. 45, no. 37, pp. 6927-6930, 2004.

[14] R. M. Meixner, H. Göbel, F. A. Yildirim, W. Bauhofer, and W. Krautschneider, "Wavelength-selective organic field-effect phototransistors based on dye-doped poly-3-hexylthiophene," Applied Physics Letters, vol. 89, no. 9, Article ID 092110, 2006.

[15] C. C. Wu, J. C. Sturm, M. E. Thompson, R. A. Register, E. P. Dana, and J. Tian, "Efficient organic electroluminescent devices using single layer doped polymer thin films with bipolar carrier transport abilities," IEEE Transactions on Electron Devices, vol. 44, no. 8, pp. 1269-1281, 1997.

[16] T. Yamanari, T. Taima, J. Sakai, and K. Saito, "Origin of the open-circuit voltage of organic thin-film solar cells based on conjugated polymers," Solar Energy Materials and Solar Cells, vol. 93, no. 6-7, pp. 759-761, 2009. 
[17] M. T. Lloyd, A. C. Mayer, S. Subramanian et al., "Efficient solution-processed photovoltaic cells based on an anthradithiophene/fullerene blend," Journal of the American Chemical Society, vol. 129, no. 29, pp. 9144-9149, 2007.

[18] A. B. Tamayo, X. D. Dang, B. Walker, J. Seo, T. Kent, and T. Q. Nguyen, "A low band gap, solution processable oligothiophene with a dialkylated diketopyrrolopyrrole chromophore for use in bulk heterojunction solar cells," Applied Physics Letters, vol. 94, no. 10, pp. 103301-103303, 2009.

[19] J. Sakai, T. Taima, T. Yamanari, and K. Saito, "Annealing effect in the sexithiophene: $\mathrm{C}_{70}$ small molecule bulk heterojunction organic photovoltaic cells," Solar Energy Materials and Solar Cells, vol. 93, no. 6-7, pp. 1149-1153, 2009.

[20] Y. Zhao, Z. Xie, Y. Qu, Y. Geng, and L. Wang, "Effects of thermal annealing on polymer photovoltaic cells with buffer layers and in situ formation of interfacial layer for enhancing power conversion efficiency," Synthetic Metals, vol. 158, no. 2124, pp. 908-911, 2008.

[21] G. Li, V. Shrotriya, Y. Yao, and Y. Yang, "Investigation of annealing effects and film thickness dependence of polymer solar cells based on poly(3-hexylthiophene)," Journal of Applied Physics, vol. 98, no. 4, pp. 043704-043708, 2005.

[22] P. Vanlaeke, A. Swinnen, I. Haeldermans et al., "P3HT/PCBM bulk heterojunction solar cells: relation between morphology and electro-optical characteristics," Solar Energy Materials and Solar Cells, vol. 90, no. 14, pp. 2150-2158, 2006.

[23] H. Kim, W. W. So, and S. J. Moon, "Effect of thermal annealing on the performance of $\mathrm{P} 3 \mathrm{HT} / \mathrm{PCBM}$ polymer photovoltaic cells," Journal of the Korean Physical Society, vol. 48, no. 3, pp. 441-445, 2006.

[24] Y. A. M. Ismail, T. Soga, and T. Jimbo, "Photovoltaic properties of bulk heterojunction organic solar cell composed of coumarin 6 dye as light harvester and donor material," Japanese Journal of Applied Physics, vol. 49, no. 5, Article ID 052301, pp. 1-7, 2010.

[25] W. J. Yoon, K. Y. Jung, J. Liu et al., "Plasmon-enhanced optical absorption and photocurrent in organic bulk heterojunction photovoltaic devices using self-assembled layer of silver nanoparticles," Solar Energy Materials and Solar Cells, vol. 94, no. 2, pp. 128-132, 2010.

[26] Y. M. Chang, W. Su, and L. Wang, "Influence of photo-induced degradation on the optoelectronic properties of regioregular poly(3-hexylthiophene)," Solar Energy Materials and Solar Cells, vol. 92, no. 7, pp. 761-765, 2008.

[27] S. Kazim, M. Zulfequar, M. M. Haq, P. K. Bhatnagar, and M. Husain, "Electrical and optical properties of thin films based on poly [2-methoxy-5 (2'-ethyl hexyloxy)-1,4phenylene vinylene] doped with acridine orange dye with possible photovoltaic applications," Solar Energy Materials and Solar Cells, vol. 91, no. 15-16, pp. 1462-1466, 2007.

[28] J. J. Dittmer, R. Lazzaroni, P. Leclère et al., "Crystal network formation in organic solar cells," Solar Energy Materials and Solar Cells, vol. 61, no. 1, pp. 53-61, 2000.

[29] X. M. Jiang, R. Osterbacka, O. J. Korovyanko et al., "Spectroscopic studies of photoexcitations in regioregular and regiorandom polythiophene films," Advanced Functional Materials, vol. 12, no. 9, pp. 587-597, 2002.

[30] H. Hoppe, M. Niggemann, C. Winder et al., "Nanoscale morphology of conjugated polymer/fullerene based bulkheterojunction solar cells," Advanced Functional Materials, vol. 14, no. 10, pp. 1005-1011, 2004.
[31] C. D. Dimitrakopoulos and D. J. Mascaro, "Organic thinfilm transistors: a review of recent advances," IBM Journal of Research and Development, vol. 45, no. 1, pp. 11-27, 2001.

[32] H. Hoppe and N. S. Sariciftci, "Organic solar cells: an overview," Journal of Materials Research, vol. 19, no. 7, pp. 1924-1945, 2004. 

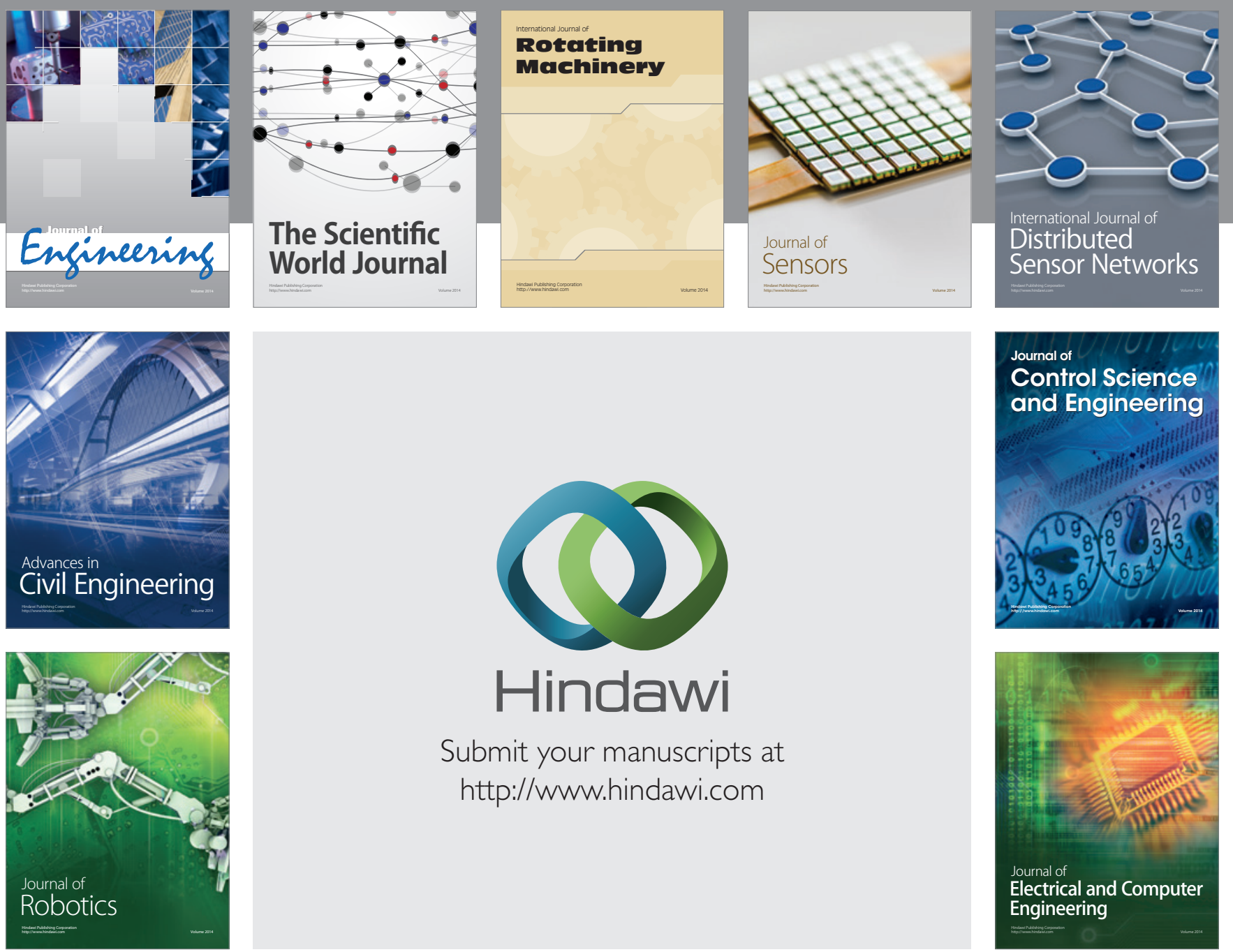

Submit your manuscripts at

http://www.hindawi.com
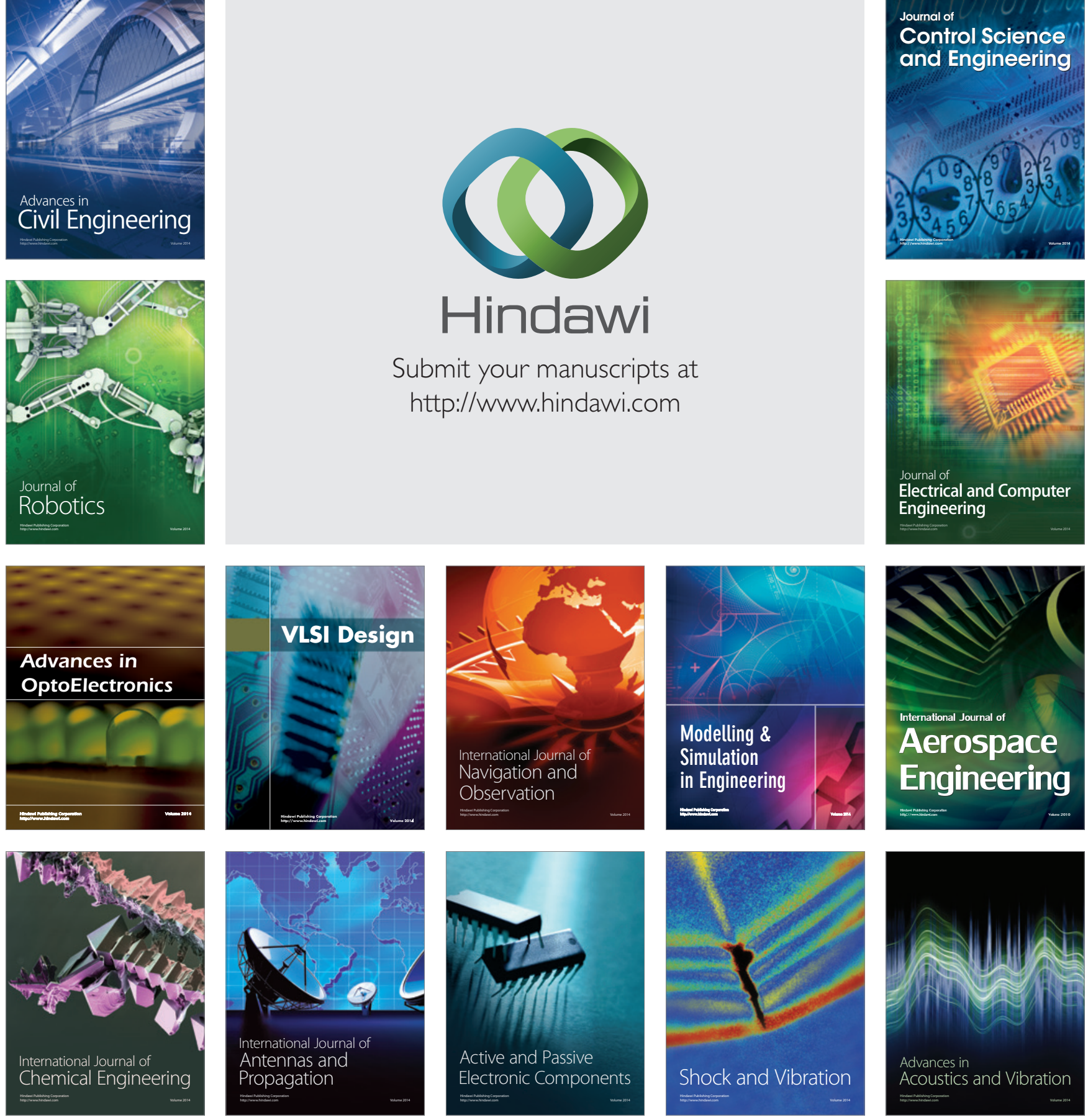